\title{
Kvinner i akademia - en trussel mot menn?
}

\begin{abstract}
SAMMENDRAG Det er hundre år siden kvinner fikk stemmerett og 120 år siden Marie Spångberg, som første kvinne, avla medisinsk embetseksamen. Nå utdannes det flere kvinner enn menn som leger, men akademiske toppstillinger er fortsatt dominert av menn. Medisinhistorien inneholder flere godt dokumenterte tilfeller av diskriminering av kvinnelige søkere ved ansettelse i akademiske posisjoner. Ut fra en gjennomgang av tilgjengelige dokumenter i Riksarkivet, merket «Det medisinske fakultet», kan det argumenteres for at Ardis Storm-Mathisen er en av dem. Hennes doktorgradsarbeid i klinisk nevrologi ble underkjent av fakultetet, til tross for at en enstemmig internasjonal komité gikk inn for godkjenning. Selv om påstanden er spekulativ, er det vanskelig å finne annen forklaring på avvisningen av Storm-Mathisens arbeid enn at hun var kvinne.
\end{abstract}

I dag er godt over halvparten av de nye legene kvinner. Kvinnene har i løpet av et århundre erobret medisinen, men den akademiske medisin er fortsatt mannsdominert. I 2006 var det flere kvinner enn menn som tok medisinsk doktorgrad, mens andelen kvinner i professor I- og professor II-stillinger var henholdsvis $20 \%$ og $10 \%$ (1).

Helt opp til våre dager er det eksempler på at kjønn spiller en rolle ved vurderingen av akademiske kvalifikasjoner (2). I Tidsskriftet er det tidligere beskrevet diskriminering av en kvinne ved ansettelse av reservelege ved Kvinneklinikken ved Rikshospitalet i 1914 (3). Ved ansettelse av professor i pediatri i 1940 skal Kirsten Utheim Toverud (1890-1949) ha blitt forbigått, høyst sannsynlig fordi hun var kvinne (4).

Det finnes også et mulig eksempel innen min egen spesialitet - klinisk nevrologi. Denne antakelsen er bygd på gjennomgang av arkivmateriale fra Det medisinske fakultet, oppbevart i Riksarkivet (5-7).

\section{Ardis Storm-Mathisen}

Ardis Storm-Mathisen (1912-2000) ble godkjent spesialist i nevrologi i 1951, som den andre norske kvinne. Den første var Hilde Mjanger (1901-77) i 1945. I 1964 ble Storm-Mathisen også godkjent spesialist i psykiatri. Hun hadde bred utdanning i klinisk nevrologi, nevrokirurgi og psykiatri, og hun var universitetsstipendiat i nevrologi og nevrofarmakologi i årene 1955-60.

Storm-Mathisen var en sentral skikkelse i det nevrobiologiske miljøet i Norge i hele siste del av 1900-tallet. Hun deltok i de fleste faglige sammenkomster, og i sosiale sammenhenger var hun med sitt elskverdige, muntre vesen midtpunktet. Ardis Storm-Mathisen var berømt for sine store hatter og sin bruk av levende blomster som dekorativ del av antrekket (fig 1).

\section{Dosenturet}

I 1955 fantes det to akademiske stillinger i klinisk nevrologi i Norge: professoratene ved Rikshospitalet og Haukeland sykehus. Dette året ble det utlyst et dosentur II i nevrologi ved Rikshospitalet i kombinasjon med en avdelingslegestilling ved Nevrologisk avdeling. Det var seks søkere, deriblant Ardis Storm-Mathisen.

Dosent i nevrologi ved Sahlgrenska Sjukhuset i Göteborg, trønderen Tore Patrick Størtebecker (1911-2002) søkte også (6). Størtebecker ble oppfattet som meget kontroversiell og uønsket i det norske miljøet (8, 9, s. 184-7). Han ble godkjent som dosentkvalifisert av fakultetet, men fikk ikke stillingen.

Komitémedlem professor i nevrokirurgi Kristian Kristiansen (1907-93) anfører i et brev til fakultetet (20.9. 1956) at «Ardis Storm Mathisen er den eneste av søkerne som kan ansees kvalifisert hvis dosent Størtebecker utelukkes fra stillingen som dosent II og avdelingslege». De to andre komitémedlemmene fant henne også kvalifisert, men førte henne opp på tredjeplass.

Det forunderlige var at én av søkerne, som bare ble godkjent av ett av komitémedlemmene (på annenplass), ble ansatt på åremål i avdelingslegestillingen og som dosent for samme tidsrom. I dag ser det ut som om Storm-Mathisen burde vært ansatt, men dokumentene inneholder ingen argumenter som viser hvorfor hun ble skjøvet til side (6).

\section{Doktorgraden}

Ardis Storm-Mathisen la ved sin søknad i 1955 et preliminært arbeid om forekomsten av og prognosen for pasienter med myasthenia gravis i Norge. Arbeidet var stort anlagt, med data fra hele landet og personlig undersøkelse av de fleste av pasientene. I september 1962 leverte hun inn det ferdige arbeidet Myasthenia gravis. A clinical study with special reference to prevalence and prognosis til bedømmelse for den medisinske doktorgrad ved Universitetet i Oslo (10) (fig 2). En meget sakkyndig komité ble oppnevnt: professor Tore Bro-

\author{
Ragnar Stien \\ ragnarstien@hotmail.com \\ Oslo
}


man (1908-83), Göteborg, professor Torben Fog (1912-87), København, og overlege Ejner Pedersen (1918-85), Århus.

Alle komitémedlemmene leverte sin innstilling i september 1963. De hadde selvfølgelig kritiske bemerkninger, men alle tre fant arbeidet verdig til à forsvares for den medisinske doktorgrad. Broman anga at «i Sverige skulle denna avhandling utan tvekan räcka för en medicine doctorsgrad». Fog konkluderte: «Det ligger et meget betydeligt arbejde $i$ indsamlingen af dette materiale, at dette i forening med den måde, hvorpå materialet er bearbejdet på, må kvalificere fuldt ud til den medicinske doktorgrad.» Ejner Pedersen var noe mer kritisk, men konkluderte: «Det forekommer mig sandsynligt, at man trods de betydelige mangler, ville acceptere afhandlingen til forsvar for den medicinske doktorgrad efter danske kriterier» (5).

Da skulle vel veien ligge åpen for disputas og eventuell feiring av den første norske kvinnelige doctor medicinae i nevrologi? Nei, slik gikk det ikke.

Her må det innskytes at det tidligere omtalte dosentur II i nevrologi ved Rikshospitalet igjen var lyst ledig. Åremålet på seks år var i ferd med å løpe ut og den sittende dosent ville ikke få prolongasjon av helsemessige årsaker. Fem interessenter meldte seg, tre av dem hadde søkt ved forrige utlysning. Ardis Storm-Mathisen var en av dem, Patrick Størtebecker en annen. Storm-Mathisen hadde lagt ved søknaden den ferdige, ikke forsvarte, avhandlingen om myasthenia gravis.

Komiteen som skulle bedømme søkernes skikkethet som avdelingslege og kvalifikasjoner som dosent i nevrologi, var professor Mogens Fog (1904-90), København, professor Arne G. Frøvig (1907-92), Bergen, og reservelege Ansgar Torvik (f. 1925), Oslo. Denne komiteen fant enstemmig at ingen av de fem søkerne var kvalifisert som dosent i nevrologi. Igjen ser det ut til å være slik at man ikke ville ha Størtebecker, til tross for hans posisjon som dosent i Göteborg. Man kunne da vanskelig finne noen av de andre bedre kvalifisert enn ham.

Nå ble den tredje søkeren fra forrige utlysning ansatt som avdelingslege og dosent (7). Fakultetsrådet godkjente dette mot én stemme. Professor Kristian Kristiansen avga et mindretallsvotum: «Jeg anser Størtebecker som kompetent til lærerstilling og henviser bl.a. til at han har innehatt dosentur ved Karolinska institutet og har dosentur ved Gøteborgs Universitet» (5).

Innstillingene fra de to komiteene, med vurdering av doktorgraden og vurdering av dosenturet, kom til fakultetet omtrent samtidig, dog slik at bedømmelsen av dosenturet kom først. Dekanus, professor Axel

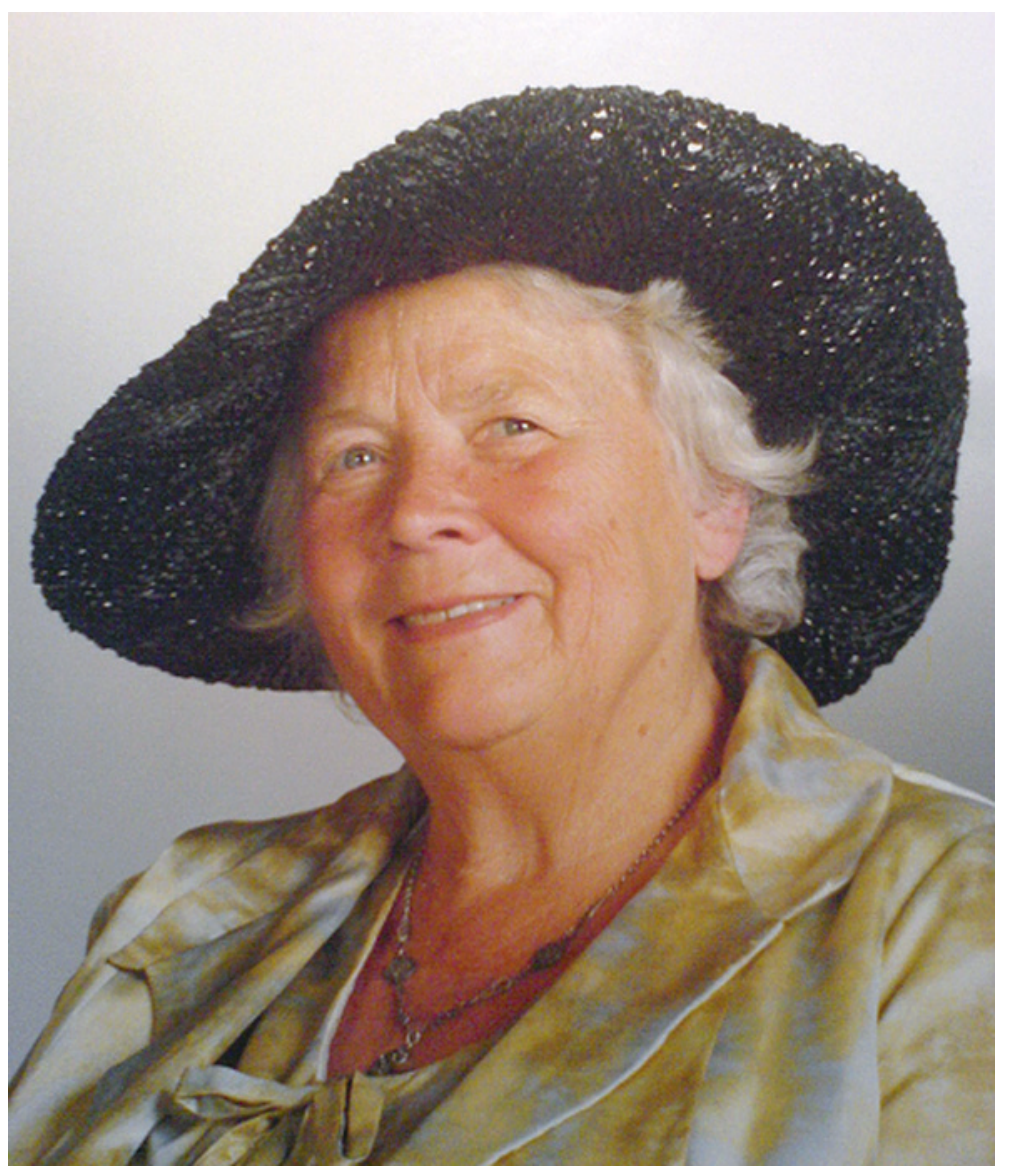

Figur 1 Ardis Storm-Mathisen (1912-2000), en fargerik kvinne. Foto: Privat

Strøm (1901-85), sendte et brev til fakultetsrådet, hvor han foreslo en utvidelse av bedømmelseskomiteen for doktorgraden. Rådet fulgte Strøms forslag. Vedtaket summeres opp slik av dekanus: «De sakkyndiges vurdering av avhandlingen divergerer imidlertid nokså meget, og da fakultetet ikke føler seg overbevist om at avhandlingen er verdig til å forsvares for doktorgraden, vedtok fakultetsrådet i møte 24 . sept. d. å. å anmode de sakkyndige ved bedømmelsen av docenturet om på grunnlag $\mathrm{av}$ den gjennomgåelse av avhandlingen som de allerede hadde foretatt, å avgi en uttalelse om de anser avhandlingen verdig til å forsvares for doktorgraden» (5).

I ettertid er det meget vanskelig å se at «de sakkyndiges vurdering divergerer nokså meget». Komiteen gikk, som nevnt, enstemmig inn for at avhandlingen kunne forsvares. Kritiske bemerkninger vil antakelig følge alle slike innstillinger. Komiteen ble da fors $ø$ kt utvidet med de tre som hadde vurdert søkerne til dosenturet. Mogens Fog og Ansgar Torvik sa seg villige.

Men fra Fog fikk fakultetet ingen tilleggsvurdering av avhandlingen, til tross for flere purringer. Torvik avga 16.12. 1963 et lengre svar og anbefalte at avhandlingen ikke skulle finnes verdig til å forsvares.

Frøvig svarte at han ikke var villig til å sitte i en utvidet komité, men avga likevel i dette svarbrevet en kort og noe halvhjertet uttalelse hvor han sier at «om jeg hadde lest den (Storm-Mathisens avhandling) med henblikk på å avgi en uttalelse om dens verdighet til å forsvares for doktorgraden, ville jeg gått grundigere til verks». Likevel fant professoren grunn til å bemerke at avhandlingen «ikke (er) jevnbyrdig med et doktorarbeide - jeg ville plassere det innen kategorien gullmedaljearbeide». Her kan det bemerkes at professoren selv ikke hadde noen doktorgrad, men et gullmedaljearbeid, noe som tidligere hadde vært et poeng da han konkurrerte om professoratet i Bergen med Patrick Størtebecker (9, s. 152-3).

\section{Avgjørelsen}

Nå ble saken liggende, uten at noen avgjørelse var tatt. Men så, 25.11. 1964, etter nesten ett år, sendte Strøm et nytt brev til fakultetsrådet og ba om at saken skulle avgjøres omgående. Han anga at svarene fra de sakkyndige forelå i september 1963 og forklarte at det var tvil (!) om avhandlingen 


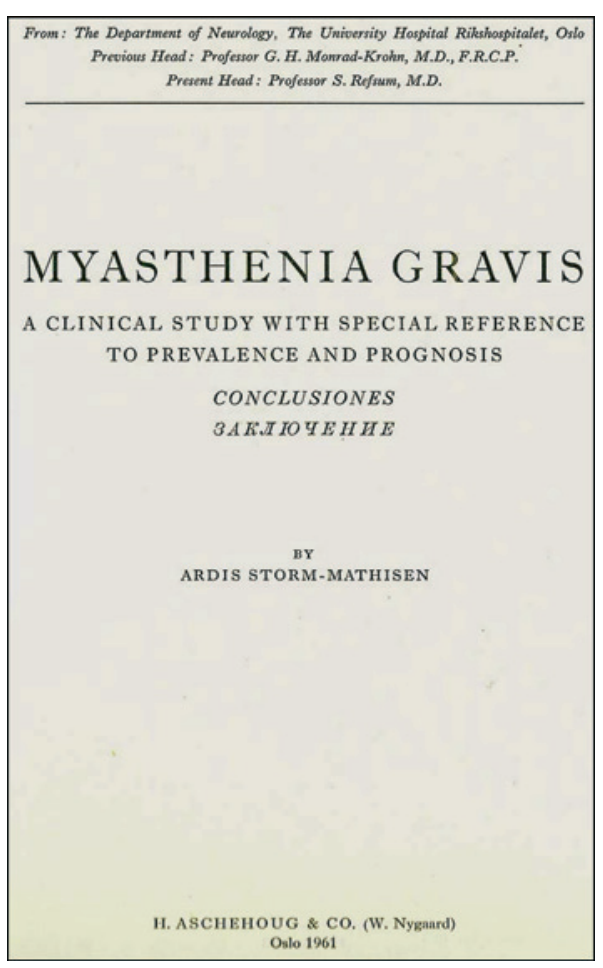

Figur 2 Storm-Mathisens store arbeid om myasthenia gravis

og hvorfor komiteen ble utvidet. Han beklaget at Mogens Fog ikke hadde svart på tross av flere purringer, og mente at «søkeren har krav på en avgjørelse nå, og at man derfor får nøye seg med de fem uttalelser som foreligger».

Her må det innskytes at det strengt tatt bare forelå fire uttalelser: Frøvigs korte brev kan ikke oppfattes som noen vurdering med premisser for en konklusjon. Strøm avsluttet sitt brev med: «Når jeg tar opp denne sak, er det fordi det var meg som foreslo utvidelse av komiteen, og jeg føler meg derfor til en viss grad ansvarlig for forsinkelsen» (7).

Her vil man nå ved gjennomgang av saken finne at Strøm i høyeste grad var ansvarlig for ikke bare forsinkelsen, men også for innstillingen han formulerte - den som fakultetsrådet 15.12. 1964 vedtok mot to stemmer. Her sies det klart at avhandlingen ikke fantes verdig til å forsvares for den medisinske doktorgrad (5). I brevet fra fakultetet til Ardis Storm-Mathisen gjentas argumentet om at «da de sakkyndiges uttalelser divergerte noe», ble avhandlingen avvist.

Denne konklusjonen må det $\mathrm{i}$ ettertid være rimelig å utfordre. En meget sakkyndig internasjonal komité på tre medlemmer fant avhandlingen verdig. Én uttalelse fra ett medlem i en utvidet komite gikk mot dette. Hvorfor ble komiteen utvidet, og hvorfor det noe uventede resultat av avstemningen i fakultetsrådet? Umiddelbart synes det ikke rimelig at reservelege Torviks vurdering skulle veie mer enn de tre veletablerte utenlandske ekspertenes votum. Hva var da begrunnelsen? Saksdokumentene gir ikke svar, men det må være lov å spekulere.

Første antakelse: Fakultetsrådsmedlemmene hadde selv lest avhandlingen og funnet den uverdig. Men det er intet i sakspapirene som gir holdepunkter for at andre enn professor Refsum (1907-91), vi må anta den mest sakkyndige i fakultetsrådet i denne saken, hadde gjort dette. Han stemte da også for godkjenning, sammen med professor Molland (1909-88).

Andre antakelse: Fordi man ikke ønsket Patrick Størtebecker i stillingen som dosent ved Rikshospitalet, kunne man heller ikke oppvurdere noen av de andre søkerne. Men ved to tidligere anledninger $(6,8)$ hadde man nettopp oppvurdert andre søkere foran Størtebecker, slik at dette neppe var noe argument for å underkjenne doktorgraden. Likevel har nok dette punktet spilt en viktig rolle ved vurderingen av dosentkompetanse.

Tredje antakelse: Man ønsket ikke en kvinne med akademiske kvalifikasjoner som mulig konkurrent til dosenturer og professorater i nevrologi. Som seniorstudent på denne tiden husker jeg godt saken om Storm-Mathisens doktorgrad. Den gang var det sterke rykter som hevdet at hun ble underkjent fordi hun var kvinne. Dette kan selvfølgelig ikke bevises, men det er vanskelig å se noen annen grunn til at hun ikke fikk forsvare sin avhandling. Det er ikke sikkert at en kvinnelig dr.med. ble oppfattet som en trussel, snarere kan det synes som om holdningen var at kvinner ikke naturlig hadde noe i akademia å gjøre.

Argumentet om de sakkyndiges store divergens er åpenbart ikke korrekt. Strøm ville uten problemer eller kritikk kunne fremmet et godkjennelsesvedtak i fakultetsrådet. Av de foreliggende brev og dokumenter (5-7) synes det som om han gjorde sitt ytterste for å hindre et slikt vedtak, enten på eget initiativ eller i samråd med andre i dag ukjente aktører. Det virker da som om dekanus, professor Axel Strøm, blir stående med ansvaret for at Ardis StormMathisens avhandling ble funnet uverdig til å forsvares for den medisinske doktorgrad. Noe personlig motsetningsforhold mellom Strøm og Storm-Mathisen har det ikke vært mulig å sannsynliggjøre. Hun var heller ikke oppfattet som noen kontroversiell person med sterkt avvikende faglige standpunkter, slik som Størtebecker.

Selv om man ikke kan konkludere sikkert i ettertid, er det i dag vanskelig å finne andre forklaringer på at Ardis Storm-Mathisen ble avvist enn at hun var kvinne. Ikke før i 1970 forsvarte en kvinne en avhandling i nevrobiologi (Kirsten Kjeldsberg Osen, f. 1928, for øvrig den første norske kvinnelige professor i medisin), og først i 1989 skjedde det samme for en kvinnelig klinisk nevrolog (11). Senere er det blitt svært mange flere, men likestilling innen akademia er ingen gammel foreteelse.

En lykkelig slutt på historien er at Ardis Storm-Mathisen i 1990, 78 år gammel, ble kreert til doctor medicinae etter å ha forsvart et arbeid over langtidsoppfølging av barn med psykiatriske forstyrrelser.

\section{Ragnar Stien (f. 1938)}

er pensjonert nevrolog.

Forfatter har fylt ut ICMJE-skjemaet og oppgir ingen interessekonflikter.

\section{Litteratur}

1. Schlichting E, Nielsen HB, Fosså SD et al. Kvinners karriereutvikling i klinisk akademisk medisin Tidsskr Nor Lægeforen 2007: 127: 2109-12.

2. Raymond J. Sexist attitudes: most of us are biased Nature 2013; 495: 33-4

3. Børdahl PE, Hem E. Fødselshjelp - et kvinnefag for mannfolk. Tidsskr Nor Lægeforen 1999; 119 4561-6.

4. Norsk biografisk leksikon. Kirsten Utheim Toverud. http://nbl.snl.no/Kirsten_Utheim_Toverud (5.3.2014).

5. Riksarkivet: Eske S-2536/1/A/Aa/L0017 (Forhandlingsprotokoll 1961-1966)

6. Riksarkivet: Eske S-2868/F/Fc/L0013 (dosenturer 1950-1966).

7. Riksarkivet: Eske merket: Tidligere avlevering, serie De - dosenturer. Denne esken inneholder bare saken: «Dosentur II komb. med avdelingslegest. på Nevrologisk avdeling, RH letter Geelmuyden)».

8. Stien R. Patrick Størtebecker - fokalinfeksjonenes profet uten anerkjennelse i sitt hjemland. Axonet 2001; nr. 3: 5-7.

9. Stien R, Aarli JA. Hjernens leger - historien om de første norske nevrologene. Oslo: Den norske nevrolitterære klubbs forlag. 2012

10. Storm-Mathisen A. Myasthenia gravis. A clinical study with reference to prevalence and prognosis. Oslo: Aschehoug, 1961

11. Heier MS. Fluoropyrimidine neurotoxicity: studies of the neurotoxic effects of 5-fluorouracil and doxifluridine and the possible relationship to thiamin (vit. B1) deficiency. Doktoravhandling. Oslo: Universitetet i Oslo, 1989

Mottatt 1.10. 2013, første revisjon innsendt 28.1 2014, godkjent 7.3. 2014. Redaktør: Kari Tveito. 